\title{
Myosin-cross-reactive antigen (MCRA) protein from Bifidobacterium breve is a FAD-dependent fatty acid hydratase which has a function in stress protection
}

Eva Rosberg-Cody ${ }^{1,2,4}$, Alena Liavonchanka ${ }^{3}$, Cornelia Göbel ${ }^{3}$, R Paul Ross ${ }^{1,4}$, Orla O'Sullivan ${ }^{4}$, Gerald F Fitzgerald ${ }^{1,2}$, Ivo Feussner ${ }^{3}$, Catherine Stanton ${ }^{1,4^{*}}$

\begin{abstract}
Background: The aim of this study was to determine the catalytic activity and physiological role of myosin-crossreactive antigen (MCRA) from Bifidobacterium breve NCIMB 702258. MCRA from B. breve NCIMB 702258 was cloned, sequenced and expressed in heterologous hosts (Lactococcus and Corynebacterium) and the recombinant proteins assessed for enzymatic activity against fatty acid substrates.

Results: MCRA catalysed the conversion of palmitoleic, oleic and linoleic acids to the corresponding 10-hydroxy fatty acids, but shorter chain fatty acids were not used as substrates, while the presence of trans-double bonds and double bonds beyond the position $\mathrm{C} 12$ abolished hydratase activity. The hydroxy fatty acids produced were not metabolised further. We also found that heterologous Lactococcus and Corynebacterium expressing MCRA accumulated increasing amounts of 10- $\mathrm{HOA}$ and 10-HOE in the culture medium. Furthermore, the heterologous cultures exhibited less sensitivity to heat and solvent stresses compared to corresponding controls.
\end{abstract}

Conclusions: MCRA protein in B. breve can be classified as a FAD-containing double bond hydratase, within the carbon-oxygen lyase family, which may be catalysing the first step in conjugated linoleic acid (CLA) production, and this protein has an additional function in bacterial stress protection.

\section{Background}

The Streptococcal $67 \mathrm{kDa}$ MCRA-like proteins represent a family of proteins which are present in a wide range of bacteria. It has been reported that some members of the MCRA-like proteins have fatty acid hydratase activity [1,2]. Recently, the MCRA protein from Streptococcus pyogenes M49 was reported to be a FAD-containing enzyme, which acts as hydratase on cis-9 (9Z) and trans-11 (11E)-double bonds of C-16, C-18 nonesterified fatty acids producing 10-hydroxy and 10,13-dihydroxy fatty acids [1].

The expression of the mcra gene was found to be upregulated by the stress responsive alternative transcription factor $\sigma^{\mathrm{B}}$ in Staphylococcus aureus [3]. It could be

\footnotetext{
* Correspondence: catherine.stanton@teagasc.ie

${ }^{1}$ Alimentary Pharmabiotic Centre, Cork, Ireland

Full list of author information is available at the end of the article
}

speculated that in vivo conditions such as high temperature at the site of infection, leading to stress in S. aureus may induce the stress responsive $\sigma^{B}$ transcription factor [3]. It is a general belief that the MCRA protein is involved in virulence in Staphylococcus and Streptococcus [4]. A $67 \mathrm{kDa}$ streptococcal MCRA protein was upregulated in group A Streptococcus during experimental mouse soft tissue infection [5] and in the asymptomatic phase of infection in cynomolgus macaques monkeys infected with group A Streptococcus [6]. However, a mcra deletion mutant in Streptococcus pyogenes showed only mild alteration in virulence properties, such as blood survival, adherence and internalization to human keratinocytes [1]. Dunman et al. (2001) found the mora gene was down-regulated by Agr, one of the most studied virulence response regulators in Staphylococcus aureus, along with other cell surface virulence factors [7]. Growth-phase associated regulation of the mcra

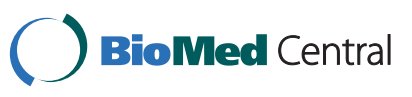

(C) 2011 Rosberg-Cody et al; licensee BioMed Central Ltd. This is an Open Access article distributed under the terms of the Creative Commons Attribution License (http://creativecommons.org/licenses/by/2.0), which permits unrestricted use, distribution, and reproduction in any medium, provided the original work is properly cited. 
gene was abrogated in a rgg mutant strain of Streptococcus pyogenes causing the mutant strain to synthesize the protein during both the exponential and stationary phases of growth, in contrast to the wild-type strain which only synthesized the protein in the exponential phase of growth. The transcriptional regulatory protein Rgg coordinates amino acid catabolism and virulence factor expression in Streptococcus pyogenes [8]. Also, the mcra gene was up-regulated by the $m g r A$ regulon in Stapylococcus aureus. This regulon has been shown to affect multiple Staphylococcus aureus genes involved in virulence and antibiotic resistance, but also genes involved in osmotic stress response (opuD (N315SA1987, encoding the glycine betaine transporter), proP (N315-SA0531, encoding a proline/betaine transport homolog) and $g b s A$ (SA2406, encoding glycine betaine aldehyde dehydrogenase)) [9].

The MCRA protein shows over $50 \%$ homology with linoleate isomerases from Lactobacillus acidophilus (Genbank: ABB43 157.1) and Lb. reuteri PYR8 linoleate isomerase [10], a protein that catalyses the formation of (9Z, 11E)-CLA from linoleic acid. CLA refers to several positional $(9,11 ; 10,12 ; 11,13$; etc.) and geometric (cis or trans) isomers of linoleic acid C18:2 cis-9 (c9), cis-12 (c12) octadecadienoic acid] with conjugated double bonds, and the $(9 \mathrm{Z}, 11 \mathrm{E})$ and $(10 \mathrm{E}, 12 \mathrm{Z})$ isomers in particular, have been shown to exert beneficial effects on human metabolism, including anti- carcinogenic, antidiabetogenic and anti-atherogenic activities and body composition alteration effects. CLA is formed via biotransformation of linoleic acid, as a direct result of the action of the ruminal microbiota, of which Butyrivibrio fibrisolvens is the foremost [11-13]. The mechanism of microbial production of CLA was characterised using washed cells of the strain Lb. acidophilus AKU 1137 [14] and involves the production of hydroxy fatty acids as precursor to formation of CLA. When isolated and introduced to the washed cells, these hydroxy fatty acids were rapidly transformed to their respective CLA isomers. Thus, CLA formation by $L b$. acidophilus was found to consist of two distinct steps, step one: the hydration of linoleic acid to 10-hydroxy-18:1 and step two: the subsequent dehydration and isomerisation of these hydroxy fatty acids to the $c 9, t 11$ CLA and $t 9, t 11$ CLA isomers.

We have previously reported the ability of a range of Bifidobacterium spp. to produce the $c 9, t 11$ CLA isomer from free linoleic acid [15-17] and have shown that administration of CLA producing $B$. breve NCIMB 702258 to mice and pigs in combination with linoleic acid alters host tissue fatty acid composition [18], including elevated liver $c 9, t 11$ CLA, coupled with reductions in the proinflammatory cytokines tumour necrosis factor- $\alpha$ (TNF- $\alpha)$ and interferon- $\gamma($ IFN- $\gamma)$. The enzyme responsible for CLA production in Bifidobacterium has not been reported. The aims of this study were 1) to investigate if the MCRA protein from $B$. breve NCIMB 702258 was active as a fatty acid hydratase, by introducing the gene encoding MCRA into Corynebacterium glutamicum and Lactococcus lactis and analysis of the enzymatic activity of the expressed protein in the heterologous hosts and 2) to investigate whether this led to increased stress tolerance in the new hosts, and thus we report a role for MCRA in stress protection in B. breve.

\section{Methods}

\section{Cultures and media}

B. breve NCIMB 702258 was cultured in MRS media (pH 6.0, Oxoid Ltd, Hampshire, UK) supplemented with 0.05\% (w/v) L-cysteine hydrochloride (Sigma Chemical, 98\% pure) under anaerobic conditions using anaerobic jars with 'Anaerocult A' gas packs (Merck, Darmstadt, Germany) at $37^{\circ} \mathrm{C}$. Lactococcus lactis NZ9800 (a L. lactis NZ9700 derivative which does not produce nisin because of a deletion in the nisA gene, and contains the nisRK signal transduction genes integrated on the chromosome) was cultured at $30^{\circ} \mathrm{C}$ in M17 (Difco laboratories, USA) broth and/or agar containing glucose $(0.5 \%$ $\mathrm{w} / \mathrm{v})$. L. lactis carrying the plasmid pNZ8048 was routinely cultured in the presence of chloramphenicol $(5 \mu \mathrm{g} /$ $\mathrm{ml}$ ) as a selective marker. Corynebacterium glutamicum ATCC 13032 was cultured aerobically in BHI media (Merck, Darmstadt, Germany) at $37^{\circ}$ C. C. glutamicum ATCC 13032 carrying the shuttle vector pCLIK 5a MCS Pddh (BASF, Ludwigshafen, Germany) was routinely cultured in the presence of kanamycin $(20 \mu \mathrm{g} / \mathrm{ml})$ as a selective marker. Escherichia coli JM109(DE3) carrying the plasmid pOXO4 was routinely cultured aerobically in $\mathrm{BHI}$ at $37^{\circ} \mathrm{C}$ in the presence of chloramphenicol $(25 \mu \mathrm{g} / \mathrm{ml})$ as a selective marker.

\section{DNA sequence analysis and primer design}

The sequence encoding the $67 \mathrm{kDa}$ MCRA (linoleate isomerase) protein from $L b$. reuteri PYR8 [19] was compared to sequence databases (GenBank and unfinished genomes databases), using the BLAST suite of programs [20]. Proteins exhibiting significant similarity were aligned using DNAStar software (DNAStar Inc. Madison, WI, USA) and conserved motifs were identified. Degenerate oligonucleotide primers and primers specific for bifidobacteria (considering bifidobacteria codon usage) were designed to these motifs (YWXTMF AFE and DTVFTTEYS, Figure 1) and used in PCR reactions to amplify a $\sim 1 \mathrm{~kb}$ internal region of the sequence as follows: Primer EV1a forward and EV2a reverse general, degenerate): 5' - TA(C/T),TGG,III,ACI,ATG,TT(C/T), GCI,TT(C/T),GA(A/G)-3' and 5'- GA,GA(T/A),(T/C) TC,IGT,IGT,(G/A)AA,IAC,IGT,(G/A)TC 3', EV1b 


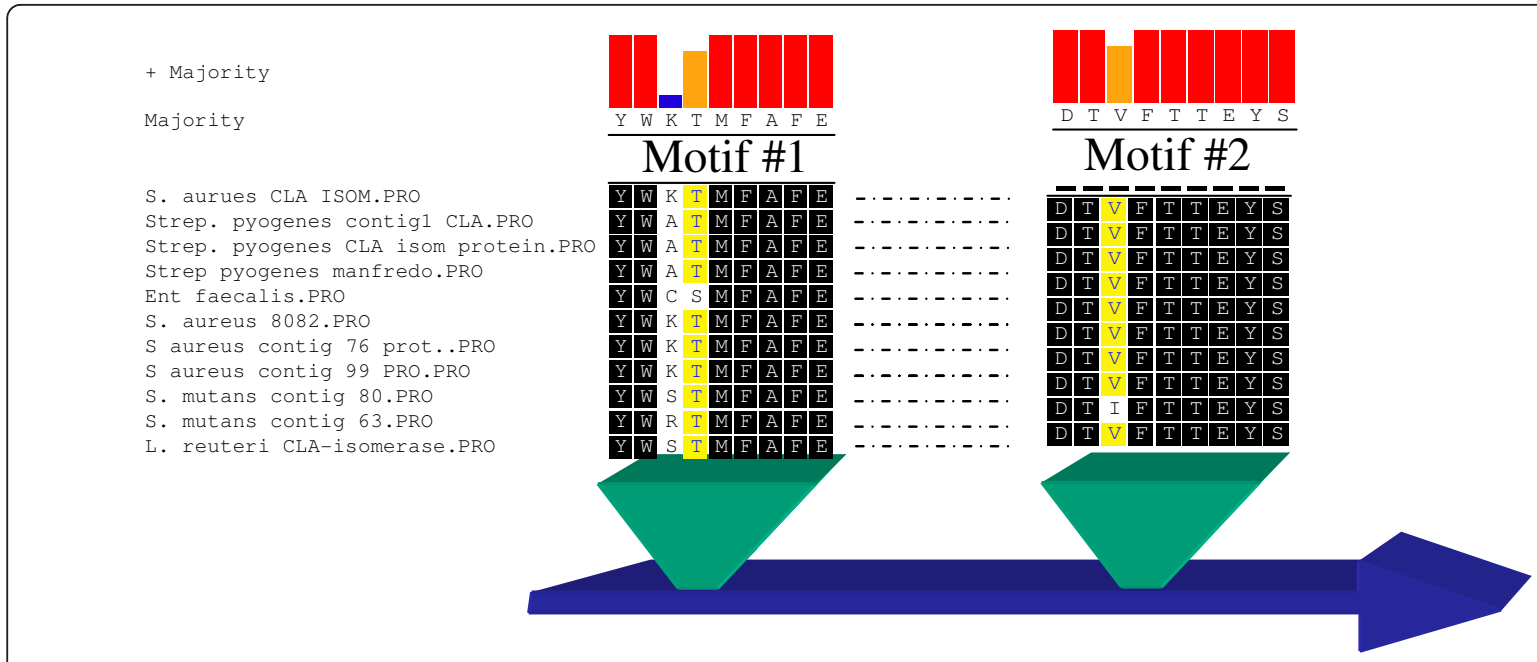

Figure 1 Motifs used to design forward and reverse primers targeted to B. breve NCIMB 702258 mcra gene.

forward and EV2b reverse (specific for bifidobacteria codon usage): 5'-TAC,TGG,III,ACC,ATG,TTC,GCI, TTC,GAA-3' and 5'- GA,GTA,TTC,(G/A)GT,(G/A)GT, GAA,GAC,(G/A)GT,(G/A)TC 3'. PCR reactions were performed in a Hybaid PCR Express Unit (Hybaid Ltd. Middlesex, UK) in $50 \mu \mathrm{l}$ with an annealing temperature of $45^{\circ} \mathrm{C}$. Each reaction contained $1 \mu \mathrm{l}$ of each primer (50 pmol/ $\mu \mathrm{l}), 2 \mu \mathrm{l}$ of template in $5 \mu \mathrm{l} \mathrm{MgCl} 2(50 \mathrm{mM})$, $5 \mu \mathrm{l}$ dNTP Master Mix (12.5 mM), $50 \mu \mathrm{l}$ 10x NH4 Reaction Buffer and $0.5 \mu$ l Biotaq DNA Polymerase $(5 \mathrm{U} / \mu \mathrm{l})$ (BIOLINE, London, UK). The resulting $\sim 1 \mathrm{~kb}$ fragment was cloned into pCR 2.1- TOPO and sequenced (MWG, Germany).

\section{Chromosome walking by inverse PCR}

To obtain flanking chromosomal sequence, two primers were designed to terminal regions of the known chromosomal DNA sequence (Additional file 1). The genomic DNA from B. breve NCIMB 702258 was digested with a range of restriction enzymes followed by ligation with DNA ligase as described by the supplier (New England BioLabs Inc. Hertfordshire, UK). The circularized fragments were subsequently used as templates in the inverse PCR reactions with the terminal primers. The reactions were performed in the same way as the standard PCR reactions but with an annealing temperature of $50^{\circ} \mathrm{C}$ and the resulting fragments (analysed after separation by agarose gel electrophoresis) were cloned into the pCR2.1-TOPOvector and sequenced. The two terminal primers used were Primer A (upstream): 3'CGTTCTCGACCTTGGTGTTGTATCGGAATT 5' and Primer B (downstream): 5' -GTACCGACCGACAA GATCGAGTCGCTTGCC-3'. From the approach described above, it was confirmed by sequencing that the 3 ' end of the gene was obtained from re-circularized
$\mathrm{XbaI}$ digests; however the 5' end was not yet acquired. A second round of inverse PCR was performed with primers A (upstream) (3'- CGTTCTCGACCTTGGTG TTGTATCGGAATT-5') and pCS0 1 (downstream) (5' GCATCGATGTCAGCCAGG-3') targeted to re-circularized $K p n I$ digests of genomic DNA, which provided another $370 \mathrm{bp}$ of the upstream region of the gene. The last round of inverse PCR to obtain the missing $170 \mathrm{bp}$ from the 5 ' end of the gene was carried out with primers ER001 (5'-TCGATGGAGGGAATCGAA-3') and ER002 (5'-TATTGGCTCAACAAGGAAGAT-3') targeted to circularized HaeII digests.

\section{DNA manipulations and plasmid construction}

Genomic DNA was isolated from $B$. breve NCIMB 702258 by a modified method described by Hoffmann et al. (1987) [21]. The 1878 mcra gene from B. breve NCIMB 702258 (Genbank: HQ593838) was amplified from genomic DNA with primers EMY01 and EMY02 (Table 1). PCR was performed with High Fidelity Expand Polymerase as described by the supplier (Roche Diagnostics, England) using $200 \mathrm{ng}$ genomic DNA as a template. PCR conditions were as follows: 10 cycles of $2 \mathrm{~min}, 15 \mathrm{~s}$ denaturation $\left(94^{\circ} \mathrm{C}\right), 30 \mathrm{~s}$ annealing $\left(55^{\circ} \mathrm{C}\right)$, 2 min elongation $\left(72^{\circ} \mathrm{C}\right.$ ) followed by 20 cycles of $15 \mathrm{~s}$ $\left(94^{\circ} \mathrm{C}\right), 30 \mathrm{~s}\left(55^{\circ} \mathrm{C}\right), 2 \mathrm{~min}+5 \mathrm{~s} /$ cycle $\left(72^{\circ} \mathrm{C}\right)$ and finally, one 7 min cycle at $72^{\circ} \mathrm{C}$.

The mora gene was amplified with primers EMY03 and EMY04 (Table 1) for cloning in pCLIK, resulting in the construct pEMYC2 which was transformed into C. glutamicum. Recombinant plasmids were double digested with the same enzymes to verify the correct clone and electroporated into L. lactis NZ9 800 and C. glutamicum ATCC 13032. Electrocompetent L. lactis were prepared and transformed according to the method 
Table 1 Primers used in this work. Restriction sites are underlined

\begin{tabular}{|c|c|c|c|}
\hline Primer & Restriction site & Resulting construct & Sequence \\
\hline EMY01 & Pstl & pEMYL1 & $5^{\prime}$ - AACTGCAGTGGATTGTCAATTCATCCCC- $3^{\prime}$ \\
\hline EMY02 & Hindlll & & $5^{\prime}$ - CCCCAAGCTTGCCCGATTATGCGAACGGCT- 3' \\
\hline EMY03 & Ndel & pEMYC2 & $5^{\prime}$ - AACATATGTGGATTGTCAATTCATCCCC- $3^{\prime}$ \\
\hline EMY04 & Avrll & & 5' - CCCCCCTAGGGCCCGATTATGCGAACGGCT- 3' \\
\hline BBI_fw2 & Ndel & $\mathrm{pBBI} 2$ & $5^{\prime \prime}$ - AACATATGTACTACAGCAGCGGCAACTATGAG- $3^{\prime}$ \\
\hline BBI_rv2 & Xhol & & $\overline{5^{\prime}-\mathrm{TCTCGAGTTAGATCACATGGTATTCGCGTAGCAGGGTAGC-} 3{ }^{\prime}}$ \\
\hline
\end{tabular}

described by de Ruyter et al. (1996) [22], while electrocompetent C. glutamicum cells were prepared as described by Luchansky et al. (1988) [23]. For enzymatic assays, the recombinant $B$. breve MCRA protein was produced in E. coli as N-terminal 6x His-tag fusion. The complete mcra gene was amplified using primers BBI_fw2 and BBI_rv2 (Table 1). Ligation with pET28 vector (Novagen) resulted in a construct pBBI2 containing $\mathrm{N}$-terminal fusion of $6 \mathrm{x}$ His tag and B. breve MCRA protein. The authenticity of the clones was verified by sequencing (MWG-BIOTECH, Germany).

\section{Investigation of the stress tolerance of MCRA protein- overproducing $L$. lactis and C. glutamicum}

The MCRA protein was expressed in lactococci using the NICE system [22], which allows maximal protein expression at sub-lethal concentrations of nisin, and is tightly controlled, such that there is negligible expression in the absence of nisin [24]. The MCRA protein was also expressed in C. glutamicum using the shuttle vector pCLIK 5a MCS Pddh. This vector replicates in both E. coli and C. glutamicum and contains a C. glutamicum promoter (ddh promoter) and a kanamycin resistance gene which function in both E. coli and C. glutamicum. L. lactis pNZ8048 and pEMYL1 cells were induced with nisin $(10 \mathrm{ng} / \mathrm{ml})$ at OD600 $\mathrm{nm} \sim 0.5$ and cultures were left to grow for an additional $1.5 \mathrm{~h}$ prior to heat treatment. C. glutamicum pCLIK and pEMYC2 were grown to OD600 $\mathrm{nm} \sim 0.4-0.5$, prior to stress. Thermotolerance of L. lactis and C. glutamicum was monitored at $51^{\circ} \mathrm{C}$ in broth over 30-40 min. Aliquots were removed at $0,10,20,30$ and $40 \mathrm{~min}$, plated on agar and incubated at $30^{\circ} \mathrm{C}$ (L. lactis) and $37^{\circ} \mathrm{C}$ (C. glutamicum) for 72 h. Salt tolerance was determined following resuspension in broth containing $3 \mathrm{M} \mathrm{NaCl}$ (L. lactis) and $4.8 \mathrm{M} \mathrm{NaCl}$ (C. glutamicum) and culture viability was monitored over 60-90 min with aliquots taken at $15 \mathrm{~min}$ intervals. Solvent tolerance was determined on addition of butanol $1-5 \%(\mathrm{v} / \mathrm{v})$, and survival was monitored over 90 min with aliquots taken at 15 min intervals.

\section{Heterologous expression, protein extraction and SDS- PAGE}

The putative linoleic acid isomerase was expressed in pOXO4 in E. coli using the T7 system (pOXO4 is a T7 RNA polymerase dependent expression plasmid). E. coli pOXO4 (control) and E. coli pEMYE3 cultures were aerated vigorously until the OD600 ${ }_{\mathrm{nm}}$ reached approximately 0.6 , at which point isopropyl- $\beta$-D-thiogalactopyranoside (IPTG) was added to final concentration of $0.5 \mathrm{mM}$ to induce expression of the T7 RNA polymerase. Aliquots were taken at intervals after IPTG induction at 1, 3, 6 and $12 \mathrm{~h}$ for whole cell protein extraction and sodium dodecyl sulfate-polyacrylamide gel electrophoresis (SDSPAGE). Similarly, L. lactis pEMYL1 and pNZ8048 (vector control) were cultured to OD $600_{\mathrm{nm}} \sim 0.5$ and induced with nisin $(10 \mathrm{ng} / \mathrm{ml})$ and allowed to grow for another $12 \mathrm{~h}$ prior to protein extraction. C. glutamicum pEMYC2 and pCLIK (vector control) were cultured as described previously for $24 \mathrm{~h}$ prior to protein extraction. To extract proteins, cells $(9 \mathrm{ml})$ were harvested and washed in $20 \mathrm{mM}$ Tris $\mathrm{HCl}, \mathrm{pH} 7.5$ and resuspended in $0.5 \mathrm{ml}$ extraction solution (20 mM Tris- $\mathrm{HCl}, \mathrm{pH} 7.5,8 \mathrm{M}$ Urea and Chaps $(0.5 \% \mathrm{w} / \mathrm{v}))$ and bead-beaten for $2 \times 30 \mathrm{sec}$ with $1 \mathrm{~min}$ rest on ice. The cell lysate was then centrifuged to remove beads and cell debris and the protein extracts analysed by SDS-PAGE using a Mini Protean II cell unit (Bio-Rad) by the method of Laemmli [25] with a $10 \%$ acrylamide resolving gel and $4 \%$ stacking gel. A low molecular weight standard ranging from 14,400 to 97,400 $\mathrm{Da}$ (BioRad) was used as a molecular weight marker.

\section{Production and purification of recombinant $B$. breve MCRA protein from $E$. coli}

For protein production, E. coli BL21 Star strain (Invitrogen, Darmstadt Germany) harboring pBBI2 plasmid was used. Bacteria were cultivated in 2xYT medium (tryptone $(30 \mathrm{~g} / \mathrm{L})$, yeast extract $(15 \mathrm{~g} / \mathrm{L}), \mathrm{NaCl}(5 \mathrm{~g} / \mathrm{L}))$ supplied with kanamycin $(25 \mu \mathrm{g} / \mathrm{ml})$ at $37^{\circ} \mathrm{C}$ until OD600 reached 0.6. At that point, IPTG was added to final concentration of $0.1 \mathrm{mM}$, the cells were changed to $16^{\circ} \mathrm{C}$ 
and harvested by centrifugation (10 min at $9100 \mathrm{~g}$ ) after $18 \mathrm{~h}$ induction time. Cells were resuspended in buffer $\mathrm{A}$ $(0.1 \mathrm{M}$ Tris $/ \mathrm{HCl}, \mathrm{pH} 8.0,0.15 \mathrm{M} \mathrm{NaCl})$ in $1: 3 \mathrm{v} / \mathrm{v}$ ratio, frozen in liquid nitrogen and stored at $-20^{\circ} \mathrm{C}$.

For protein purification, cells were lysed by adding lysozyme $(0.1 \mathrm{mg} / \mathrm{ml})$ and DNaseI $(1 \mu \mathrm{g} / \mathrm{ml})$ in buffer A and $10 \mathrm{mM} \mathrm{MgCl} 2$ and centrifuged for $20 \mathrm{~min}$ at 70,000 g. The supernatant was loaded on HisTrap column (GE Healthcare, Sweden), the column was washed with 10 column volumes of buffer $\mathrm{A}$, and the protein was eluted with 3 column volumes of buffer A and 0.5 M imidazol. After elution, the buffer was exchanged to buffer $\mathrm{B}(0.1 \mathrm{M}$ Tris $/ \mathrm{HCl}, \mathrm{pH} 7.5,150 \mathrm{mM} \mathrm{NaCl})$ by ultrafiltration and protein concentration was estimated spectrophotometrically using calculated absorption coefficient $\varepsilon 280=116990$.

\section{Immunoblotting}

$10 \mu \mathrm{g}$ of protein were subjected to SDS PAGE followed by protein transfer to nitrocellulose membrane at $60 \mathrm{~V}$, $4 \mathrm{~mA} / \mathrm{cm}^{2}$ gel surface for $1 \mathrm{~h}$. The membrane was washed with buffer B and blocked for one hour in buffer B containing $5 \%(\mathrm{w} / \mathrm{v})$ milk powder. His-tagged proteins were detected using anti-His tag antibody (Sigma) in combination with a secondary antibody coupled with alkaline phosphatase and nitrotetrazolium blue/5bromo-4-chloro-3-indolylphosphate staining.

\section{Spectroscopic assays}

Solution of purified B. breve MCRA protein had yellow colour, therefore for initial characterization UV-Vis spectrum of purified protein in the range 300-600 nm was recorded with a single beam absorption spectrometer (Ultrospec 2100 pro, GE Healthcare). For the reference, spectra of FAD and FMN in Buffer B were recorded in the same way. For these measurements, B. breve MCRA protein, FAD and FMN were brought within the concentration range 10-40 pM. The absence of covalent bond between cofactor and B. breve MCRA protein was confirmed in the following way; $200 \mathrm{pl}$ of the protein $(10 \mathrm{mg} / \mathrm{ml}$ in $50 \mathrm{mM}$ Tris/ $\mathrm{HCl}, \mathrm{pH} 7.5)$ was boiled for $10 \mathrm{~min}$ at $100^{\circ} \mathrm{C}$ and centrifuged at $12,000 \mathrm{~g}$ for $10 \mathrm{~min}$. The spectrum of the supernatant was then recorded as described above.

\section{Activity assay, lipid extraction and derivatization}

To demonstrate the enzymatic activity of B. breve MCRA protein, a panel of free fatty acids was tested in the reactions with the purified protein. Typically, 10-50 pg of substrate was mixed with $10 \mathrm{pg}$ of purified protein in 1 $\mathrm{mL}$ of buffer $\mathrm{B}$ and incubated for $1 \mathrm{~h}$ at $25^{\circ} \mathrm{C}$. Fatty acids were extracted from the reaction mixture with $1 \mathrm{ml}$ chloroform:methanol (1:1) according to Bligh and Dyer [26]. Free fatty acids were dissolved in methanol and converted to corresponding methyl esters with (trimethylsilyl)-diazomethane. For GC-MS analysis, fatty acid methyl esters were dissolved in acetonitrile and hydroxy groups were modified by N,O-bis-(trimethylsilyl)-trifluoroacetamide (BSTFA), resulting in fatty acid trimethylsilylethers. GC-MS analysis was performed as previously described [27].

\section{Phylogenetic analysis}

Homologs to the previously identified linoleate isomerase from Lb. acidophilus (Genbank: ABB43 157.1) and oleate hydratase, Elizabethkingia meningoseptica (Genbank: GQ144652) were selected from BLAST analysis. These homologs, along with MCRA from B. breve NCIMB 702258 discussed in this manuscript were aligned using T-Coffee [28] and protein trees were built using the PHYLIP package [29]. The cladogram was then visualised using DENDROSCOPE [30].

\section{Results}

Previous studies by Rosson et al. [10] reported on the isolation and purification of a putative linoleic acid isomerase from $L b$. reuteri. In these studies, protein sequencing had identified a $67 \mathrm{kDa}$ protein with homology to MCRA. Based on this finding, we designed primers to conserved regions shared by a range of MCRA proteins in the database (Figure 1) and found that we could PCR the gene from a range of different Bifidobacterium strains and Propionibacterium freudenreichii shermanii (Additional file 2). Given that B. breve NCIMB 702258 is known to be capable of producing $c 9$, t11 CLA from linoleic acid [16], we decided to study this strain in terms of CLA production. Using primers EV1a forward and EV2a reverse, we amplified a $1 \mathrm{~kb}$ internal fragment of the putative isomerase gene from B. breve. Sequencing of this revealed up to $70 \%$ homology to MCRA proteins from various genera. Following this, we primer walked in both 5'and 3' directions, which resulted in the full sequence of $B$. breve putative isomerase (Additional file 1).

\section{Sequence analysis}

The complete 1878 bp nucleotide sequence from $B$. breve NCIMB 702258 encodes a protein of 626 amino acids with homology to other "67 kilodalton MCRA" proteins. The calculated molecular weight of the protein is $70535.38 \mathrm{Da}$. Comparison with sequences in the database revealed that the cloned MCRA protein showed 71\% homology with putative $67 \mathrm{kDa}$ MCRA from Streptococcus mutans UA159 (Genbank: NP_720953) and 51\% homology with $L b$. acidophilus linoleate isomerase (Genbank: ABB43 157.1). A non-canonical flavin binding motif $(\operatorname{GxGxxA}(x) 21 \mathrm{E})$ is present at the N-terminus of $B$. breve MCRA protein, similar to Streptococcus and 
Lactobacillus MCRA proteins [31]. The protein is cytoplasmic, but may have one trans-membrane helix as predicted by PSORTb (http://www.psort.org/). Upstream of the ORF is a putative dehydrogenase or reductase protein with $\sim 50 \%$ homology with B. longum NCC2705 2,5diketo-D-gluconic acid reductase (Genbank: AAN24097). Downstream of the TGA stop codon is a region of dyad symmetry, capable of forming a stable stem-and-loop structure. The potential hairpin consists of 13-bp stem separated by a 3 -bp mis-priming and a 5 - bp loop $(\Delta \mathrm{G}$, $-15.01 \mathrm{kcal})$

\section{Over-expression of $B$. breve MCRA protein in E. coli}

Since no over-expression of the putative linoleic acid isomerase could be confirmed following SDS-PAGE of the recombinant lactococci and corynebacteria, possibly due to masking of the protein by other proteins of similar molecular weight (Additional file 3), the putative la $i$ (linoleic acid isomerase) gene was expressed in pOXO4 in E. coli using the T7 system (pOXO4 is a T7 RNA polymerase dependent expression plasmid). Following growth and induction at $\mathrm{OD} 600_{\mathrm{nm}} 0.6$ with $0.5 \mathrm{mM}$ IPTG, aliquots of E. coli pOXO4 (control) and E. coli pEMYE3 were taken at 1, 3, 6 and $12 \mathrm{~h}$ after induction for whole cell protein extraction and SDS-PAGE. A protein band of approximately $66 \mathrm{kDa}$ was visualized, corresponding to the expected molecular weight of the putative isomerase protein, which was absent in the IPTG induced control culture E. coli pOXO4 (Additional file 3). Following incubation for 48-72 $\mathrm{h}$ with free linoleic acid $(0.5 \mathrm{mg} / \mathrm{ml})$, the substrate for bacterial conversion to $c 9, t 11$ CLA, no isomerase activity could be confirmed among the heterologous clones carrying the lai gene in the bacterial supernatant by GC (Additional file 4), or by measuring OD234 $\mathrm{nm}$ [17].

\section{Production of $B$. breve MCRA in E. coli. and enzymatic assays}

B. breve MCRA protein was overproduced in E. coli and purified on $\mathrm{Ni}^{2+}$-NTA column (Figure $2 \mathrm{~A}$, lane 2). The major band with apparent molecular weight of $66 \mathrm{kDa}$ was visualized on SDS PAGE after the elution. Immunoblotting with anti-His tag antibodies confirmed that this band contained 6x His tag (Figure 2A, lane 3). Purified B. breve MCRA protein has flavin-like UV-Vis absorption spectrum with maxima around 450 and $370 \mathrm{~nm}$ (Figure 2B) and the flavin cofactor is released in the solution upon protein denaturation by heat. The spectral properties of $B$. breve MCRA are consistent with a recombinant MCRA protein from S. pyogenes, which was found to contain a non-covalently bound FAD and exhibited double bond hydratase activity producing 10- and 13-hydroxy fatty acids [1]. These data prompted us to examine the enzymatic activity of $B$. breve MCRA using common $\mathrm{C} 16$ and $\mathrm{C} 18$ fatty acids as substrates. To this end, purified protein was incubated with free fatty acids and the reaction products were analyzed by GC-MS. Indeed, we observed conversion of palmitoleic oleic and linoleic acids to the corresponding 10-hydroxy fatty acids (Figure 3 and Table 2), but myristoleic acid or shorter monounsaturated fatty acids were not substrates. The presence of trans-double bonds as well as

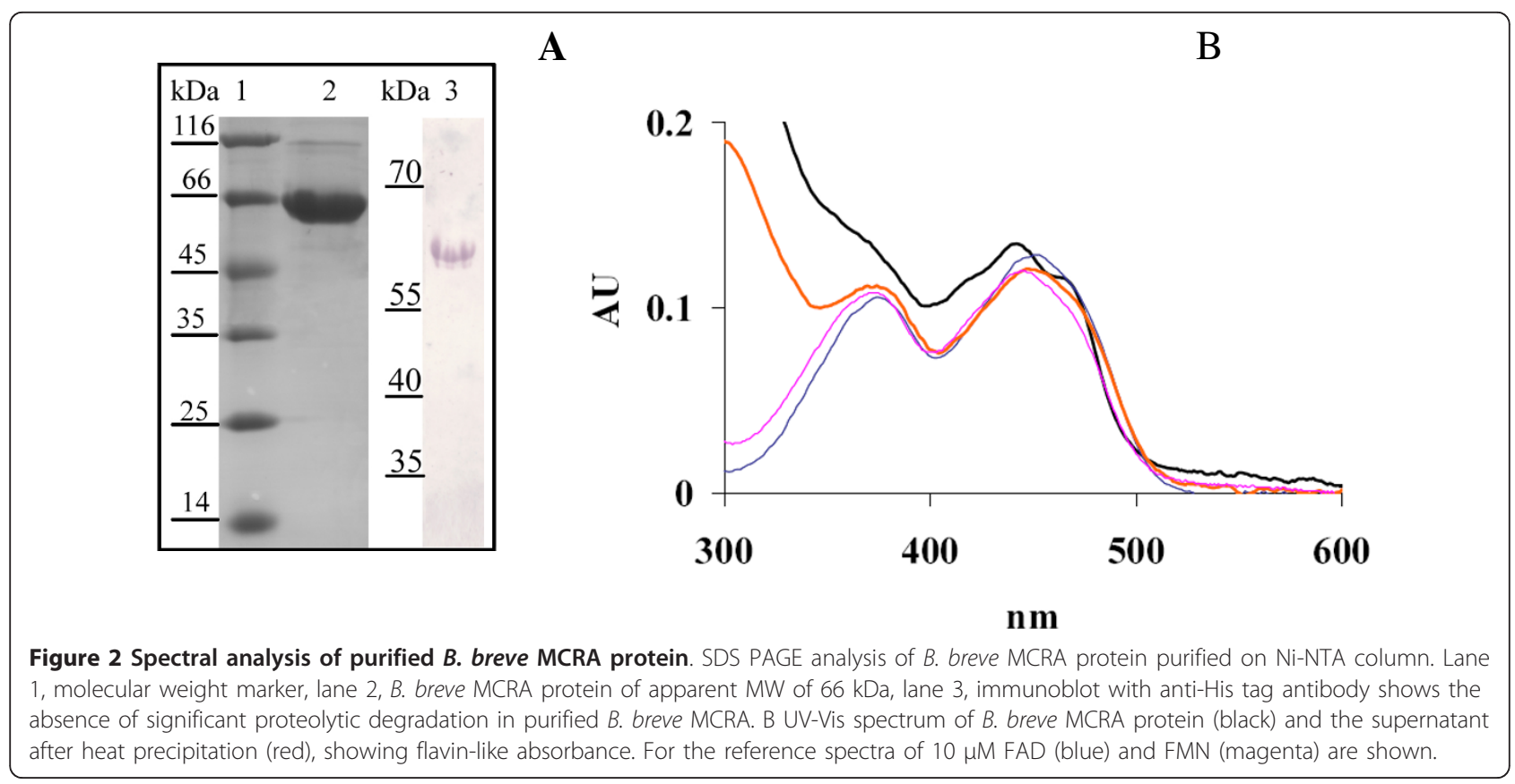




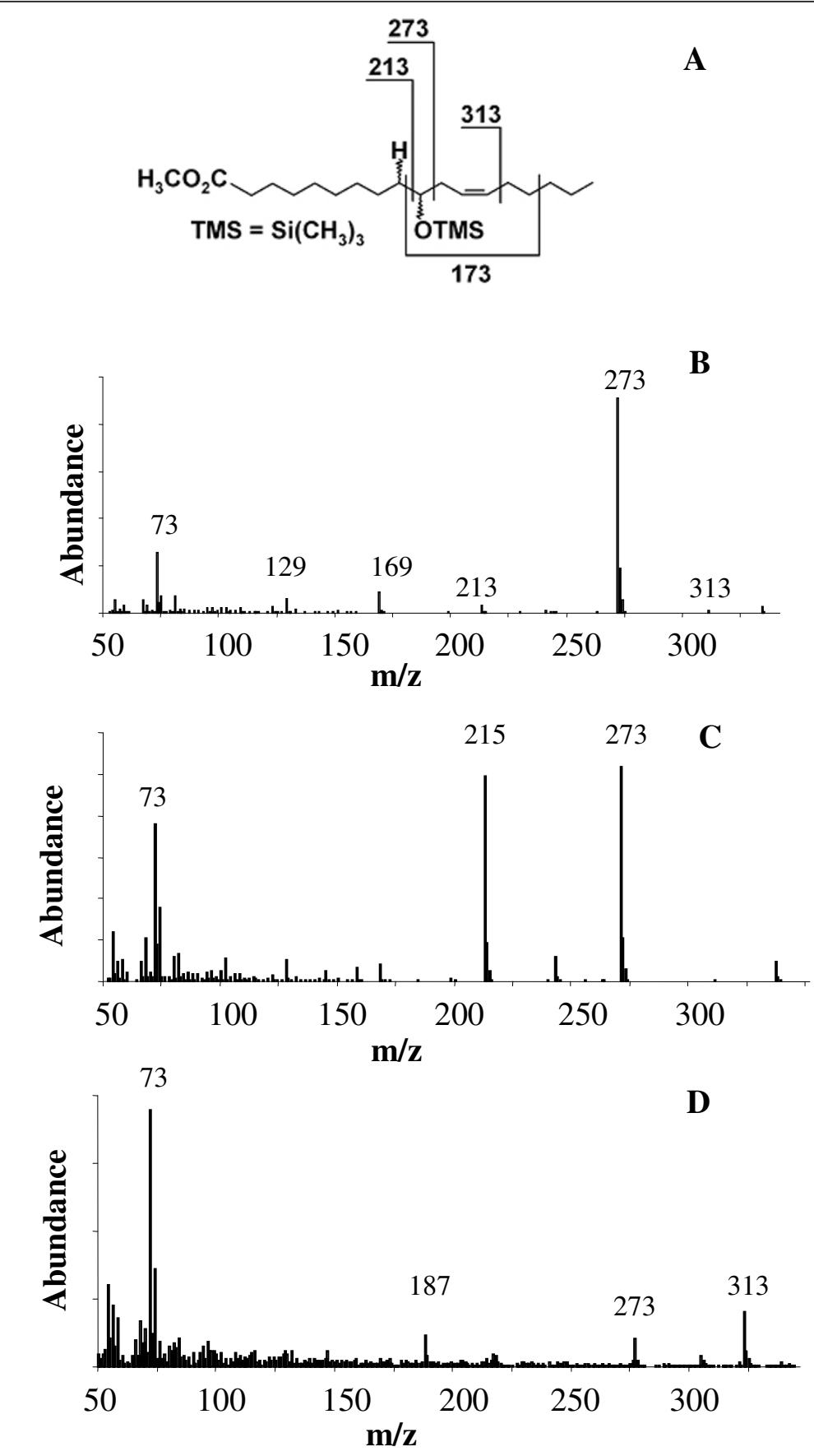

A

Figure 3 Mass spectra of reaction products from the incubations of $B$. breve MCRA protein with free fatty acids. A) Fragmentation pattern of 10-HOE. B) Mass spectrum of 10-HOE obtained after the incubation with linoleic acid. C) Mass spectrum of 10-HO obtained after the incubation with oleic acid. D) Mass spectrum of 10-HH obtained after the incubation with palmitoleic acid.

the double bonds beyond the position C12 abolished hydratase activity. No conversion of esterified fatty acids such as methyl linoleate or CLA isomers was observed.

\section{Phylogenetic analysis}

Figure 4 displays a phylogenetic analysis of MCRA from B. breve NCIMB 702258 along with both linoleate isomerase and oleate hydratase homologs. The tree clearly illustrates distinct groupings of the two sets of homologs. Interestingly, our MCRA protein branches in between both groupings but appears to be evolutionary closer to the hydratase group. This result further supports our finding of the MCRA as fatty acid hydratase. 
Table 2 Reaction products of recombinant purified B. breve MCRA protein

\begin{tabular}{|c|c|c|c|}
\hline Substrate & Product & $\begin{array}{l}\mathrm{RT}, \\
\mathrm{min}\end{array}$ & MS fragments, $\mathrm{m} / \mathrm{z}$ \\
\hline 14: $1^{\text {A9Z }}$ & $\begin{array}{l}\text { No } \\
\text { products }\end{array}$ & - & - \\
\hline $16: 1^{\mathrm{A} 9 \mathrm{Z}}(\mathrm{PA})$ & $10-\mathrm{HH}$ & 8.13 & $357(\mathrm{M}-1)^{+}, 273,187,169$ \\
\hline $18: 1^{\mathrm{A} 9 \mathrm{Z}}(\mathrm{OA})$ & $10-\mathrm{HO}$ & 9.56 & $385(\mathrm{M}-1)^{+}, 273,215,169$ \\
\hline $18: 1^{\mathrm{A} 11 Z}$ & $\begin{array}{l}\text { No } \\
\text { products }\end{array}$ & - & - \\
\hline 18: $1^{\text {A9E }}$ & $\begin{array}{l}\text { No } \\
\text { products }\end{array}$ & - & - \\
\hline $18: 2^{A 9 Z, 12 Z}(\mathrm{LA})$ & 10-HOE & 9.84 & $\begin{array}{l}383(\mathrm{M}-1)^{+}, 273,213,173, \\
169\end{array}$ \\
\hline \multicolumn{4}{|l|}{$18: 2^{\mathrm{A} 9 Z, A 12 Z}$} \\
\hline No products & & - & - \\
\hline \multicolumn{4}{|l|}{ methyl ester } \\
\hline CLA mixture & $\begin{array}{l}\text { No } \\
\text { products }\end{array}$ & - & - \\
\hline $18: 2^{A 9 E, 12 E}$ & $\begin{array}{l}\text { No } \\
\text { products }\end{array}$ & - & - \\
\hline 18: ${ }^{3 A 9 Z, 12 Z, 15 Z}$ (LeA) & $\begin{array}{l}\text { No } \\
\text { products }\end{array}$ & - & - \\
\hline $\begin{array}{l}\text { 20:4A5Z,8Z,11Z,14Z } \\
\text { (AA) }\end{array}$ & $\begin{array}{l}\text { No } \\
\text { products }\end{array}$ & - & - \\
\hline
\end{tabular}

\section{Stress tolerance of MCRA-overproducing Lactococcus and Corynebacterium}

To determine if heterologous Lactococcus and Corynebacterium containing the mcra gene exhibited improved stress tolerance, the heterologous cultures along with vector controls of Lactococcus (pNZ8048) and Corynebacterium (pCLIK) were assayed for hydratase activity by measuring 9-hydroxy fatty acids without and with linoleic acid supplementation of the medium. Indeed, those cultures that expressed MCRA/hydratase accumulated increasing amounts of 10-HOA and 10-HOE in the culture medium (Additional file 5). Next, the heterologous cultures were exposed to heat $\left(51^{\circ} \mathrm{C} \times 30-40 \mathrm{~min}\right)$, salt $(3 \mathrm{M} \mathrm{NaCl} \times 90 \mathrm{~min}-$ Lactococcus and $4.8 \mathrm{M} \mathrm{NaCl} \times$ $90 \mathrm{~min}$ - Corynebacterium) and solvent (3\% (v/v) butanol $\times$ 45-60 min) stresses. L. lactis pNZ8048 reduced in viability by $4 \mathrm{Log} \mathrm{CFU} / \mathrm{ml}$ following heat stress at $51^{\circ} \mathrm{C}$ for $40 \mathrm{~min}$, whereas $L$. lactis pEMYL1 only reduced in viability by $2 \mathrm{Log}$ CFU/ml (Figure 5A, B). The difference in survivability between $C$. glutamicum pCLIK and pEMYC2 was $~ 0.5 \mathrm{Log} \mathrm{CFU} / \mathrm{ml}$ when heat stressed at $51^{\circ} \mathrm{C}$ for $30 \mathrm{~min}$, a decline in survivability by $<0.5 \mathrm{Log}$ $\mathrm{CFU} / \mathrm{ml}$ for L. lactis $\mathrm{pEMYL1}$ and $<1 \mathrm{Log} \mathrm{CFU} / \mathrm{ml}$ for C. glutamicum pCLIK (vector control).

Similarly, when induced L. lactis pNZ8048 was exposed to solvent stress $(3 \%(\mathrm{v} / \mathrm{v})$ butanol), a decrease in viability of $>3.3 \mathrm{Log} \mathrm{CFU} / \mathrm{ml}$ was observed, whereas induced L. lactis pEMYL1 only decreased $\sim 1.5$ Log
$\mathrm{CFU} / \mathrm{ml}$ following $60 \mathrm{~min}$ in $3 \%(\mathrm{v} / \mathrm{v})$ butanol, i.e. a difference of nearly $2 \mathrm{Log} \mathrm{CFU} / \mathrm{ml}$ between the cultures under identical conditions. C. glutamicum pEMYC2 exposed to $3 \%(\mathrm{v} / \mathrm{v})$ butanol stress for $45 \mathrm{~min}$ survived $\sim 0.75 \mathrm{Log} \mathrm{CFU} / \mathrm{ml}$ better than the vector control (pCLIK) (Figure 5C-E).

Upon confirming that the clones containing the MCRA protein were less sensitive to heat and solvent stresses, we examined the hypothesis that the protein also protected the cultures from salt stress. Following growth and induction by nisin $(10 \mathrm{ng} / \mathrm{ml}$ at OD600 $\mathrm{nm}$ 0.5) and additional growth for $1.5 \mathrm{~h}$, L. lactis pNZ8048 (control) and pEMYL1 cultures were exposed to $3 \mathrm{M}$ $\mathrm{NaCl}$ for $90 \mathrm{~min}$. However, no difference in salt tolerance was observed at concentrations of $3 \mathrm{M} \mathrm{NaCl}$. A similar observation was made for C. glutamicum pCLIK and pEMYC2 which were grown in $4.8 \mathrm{M} \mathrm{NaCl}$ for 90 min. Both C. glutamicum control (pCLIK) and pEMYC2 cultures survived in $4.8 \mathrm{M} \mathrm{NaCl}$ for 90 min with no apparent decline in viable numbers (Figure 5F, G).

\section{Discussion}

Several recent reports have linked MCRA and oleic acid hydratase activity [1-3], which was first observed more than forty years ago in Pseudomonas sp. [32]. However, the significance of this hydratase activity for the bacterial host is not yet clearly established. Our study identified MCRA from $B$. breve as a FAD-containing hydratase with an additional role in stress protection (Figures 2 and 3, Table 2). Interestingly, a recent study by O'Flaherty and Klaenhammer (2010) indicated a role for MCRA in stress tolerance, cell wall division and adherence to Caco-2 cells [33]. Furthermore, all three characterized enzymes from this family are highly specific for free fatty acids as the previously characterized linoleic acid isomerase from $P$. acnes $[1,2,34]$. Thus, both enzyme activities seem to form a new class of FAD-dependent fatty acid modifying enzymes. This finding may be even further supported by phylogenetic groupings (Figure 4). Given the wide distribution of the mcra gene between human pathogenic and commensal bacteria, it could be speculated that it is not directly linked to virulence but to a general stress protection, which could also be useful for a pathogen i.e. increased heat at the site of infection. Our study confirmed the increased viability of heterologous Lactococcus and Corynebacterium transformed with the mcra gene during heat and solvent stresses as a difference in viability of 2 Log CFU/ml following heat stress at $51^{\circ} \mathrm{C}$ for $40 \mathrm{~min}$ and $3 \%(\mathrm{v} / \mathrm{v})$ butanol stress for $60 \mathrm{~min}$ was observed between L. lactis pEMYL1 and pNZ8048 (Figure 4A-E). Likewise, the introduced MCRA improved the survivability of $C$. glutamicum by $\sim 0.5 \mathrm{Log} \mathrm{CFU} / \mathrm{ml}$ difference between $C$. glutamicum pCLIK and pEMYL1 following 


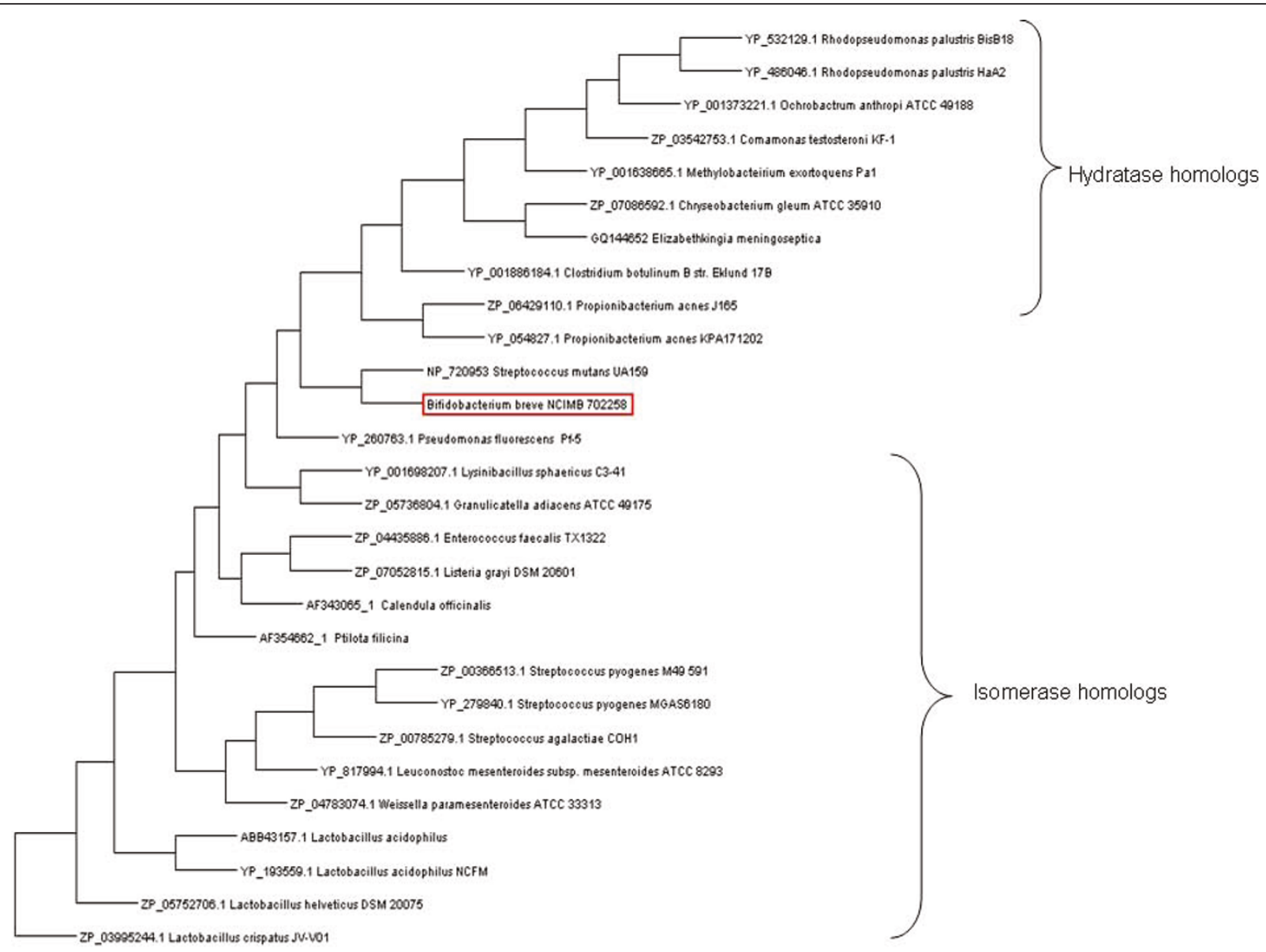

Figure 4 Phylogenetic tree of linoleate isomerase and oleate hydratase homologs. (accession numbers for each homolog are included) The placement of MCRA protein from B. breve NCIMB 702258 is highlighted in red. All branches are supported at $>75 \%$ bootstrap values.

heat stress at $51^{\circ} \mathrm{C}$ for $30 \mathrm{~min}$, and $\sim 0.75 \mathrm{Log} \mathrm{CFU} / \mathrm{ml}$ following 3\% (v/v) butanol stress for 45 min (Figure 5).

The same host, L. lactis NZ9800 has previously been used for comparative studies of stress performance following transformation with the well known heat shock protein GroESL in plasmid pNZ8048. Desmond et al. (2004) [35] compared the viability of induced (nisin $10 \mathrm{ng} / \mathrm{ml}$ ) and heat treated cells at $54^{\circ} \mathrm{C}$ for $30 \mathrm{~min}$ of the same host $L$. lactis NZ9800 transformed with either pNZ8048 or pNZ8048-GroESL. At that temperature, both L. lactis pNZ8048 and un-induced L. lactis pNZ8048-GroESL (pGRO1) reduced in viability by 4.0 $\log \mathrm{CFU} / \mathrm{ml}$, whereas the induced L. lactis (pGRO1) declined by $3.3 \mathrm{Log} \mathrm{CFU} / \mathrm{ml}$ during the heat stress. Furthermore, induced GroESL-overproducing L. lactis (pGRO1) was able to grow and increase by $0.5 \mathrm{Log}$ $\mathrm{CFU} / \mathrm{ml}$ during $5 \mathrm{~h}$ exposure to $0.5 \%(\mathrm{v} / \mathrm{v})$ butanol, compared with L. lactis (pNZ8048) and un-induced L. lactis (pGRO1) which declined in viability after $1 \mathrm{~h}$ $(0.2 \mathrm{Log} \mathrm{CFU} / \mathrm{ml})$, a trend that continued over the $6 \mathrm{~h}$ period of solvent challenge.
It has been reported that the response of cells to sublethal heat and ethanol exposure induce essentially identical stress responses because of the alteration in the membrane fluidity by these stresses [36]. Heat and ethanol stresses cause similar changes to plasma membrane protein composition, reducing the levels of plasma membrane $\mathrm{H}^{+}$- ATPase protein and inducing the plasma membrane-associated Hsp30. Both stresses also stimulate the activity of the fraction of $\mathrm{H}^{+}$-ATPase remaining in the plasma membrane. The resulting enhancement to catalysed proton efflux from the cell represents a considerable energy demand, yet may help to counteract the adverse effects for homeostasis of the increased membrane permeability that results from stress.

\section{Conclusions}

This study has shown that the MCRA protein in bifidobacteria is a FAD containing hydratase enzyme, which may be catalysing the first step in CLA production in this species, and has an additional function in bacterial stress protection. 
A

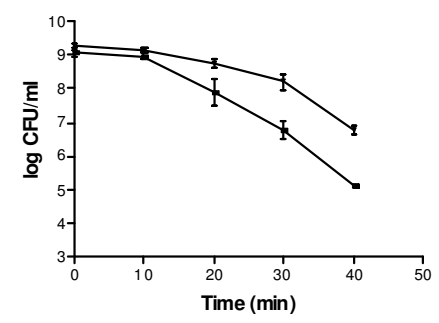

C

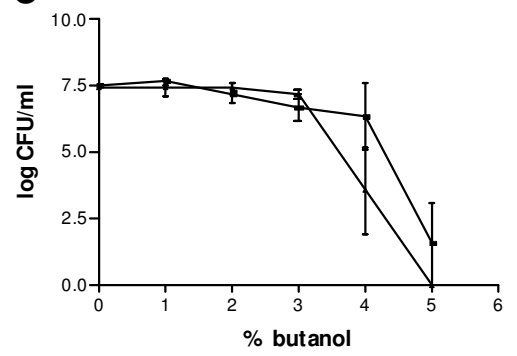

E

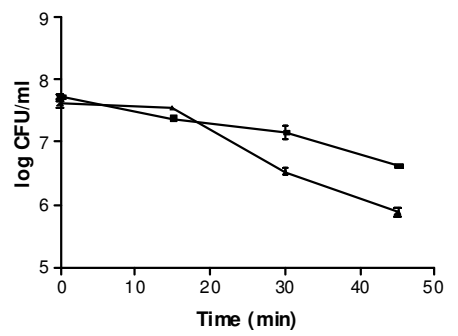

G

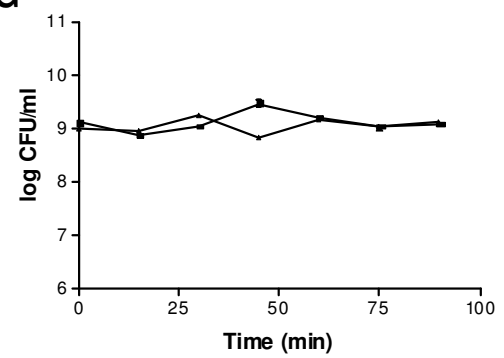

B

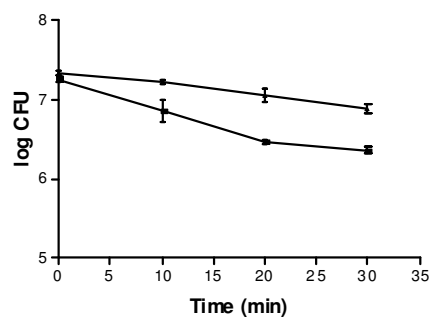

D

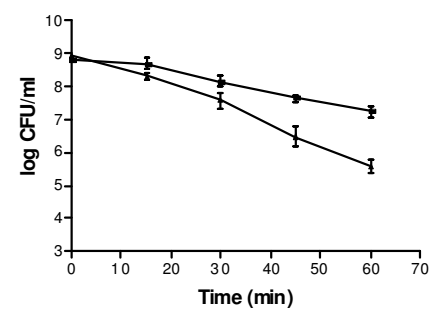

$\mathbf{F}$

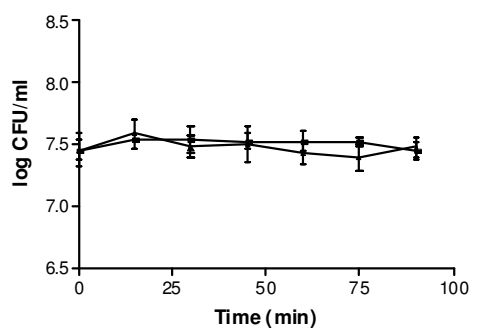

Figure 5 Effect of $B$. breve MCRA expression on survivability of $L$. lactis and C. glutamicum strains under stress conditions A) Survivability of L. lactis pNZ8048 ('black square') versus pEMYL1 ('upside down black triangle') following heat treatment at $51^{\circ} \mathrm{C}$ for $40 \mathrm{~min}$. ${ }^{* *}$ Denotes value significantly different $(p=0.01$ ) than control (pNZ8048). B) Survivability of C. glutamicum pCLIK ('black square') versus pEMYC2 ('black triangle') following heat treatment at $51^{\circ} \mathrm{C}$ for $30 \mathrm{~min} *$ Denotes value significantly different $(p=0.05)$ than control (C. glutamicum pCLIK). C) Survivability of C. glutamicum pCLIK ('upside down black triangle') versus pEMYC2 ('black square') following growth in 1-5\% (v/v) butanol for 1 h. D) Survivability of L. lactis pNZ8048 ('black triangle') versus pEMYL1 ('black square') following nisin induction for 1.5 h prior to growth in 3\% $(\mathrm{v} / \mathrm{v})$ butanol for $1 \mathrm{~h}$. The experiments were done at least in triplicate. * Denotes value significantly different $(p=0.05)$ than control (pNZ8048). E) Survivability of C. glutamicum pCLIK ('upside down black triangle')versus pEMYC2 ('black square') following growth in 3\% ( $/$ /v) butanol for 45 min. F) Survivability of C. glutamicum pCLIK ('black triangle')versus pEMYC2 ('black square') following growth in $4.8 \mathrm{M}$ NaCl for 90 min.

G) Survivability of L. lactis pNZ8048 ('black triangle') versus pEMYL1 ('black square') following nisin induction for $1.5 \mathrm{~h}$ prior to growth in 3 M NaCl for $90 \mathrm{~min}$. The experiments were done in triplicate. 


\section{Additional material}

Additional file 1: Map of putative isomerase gene. Map of putative isomerase gene and chromosome walking strategy (inverse PCR) used to obtain the full sequence.

Additional file 2: Mcra gene sequence data from Bifidobacterium strains and Propionibacterium freudenreichii shermanii. $1 \mathrm{~kb} P C R$ fragments following PCR of genomic DNA from a range of bifidobacterial strains and Propionibacterium freudenreichii shermanii 9093 using oligonucleotide primers EV1a forward and EV2a reverse. Lanes 1-12 in the following order; $B$. adolescentis; $B$. breve $2257 ; B$. breve 702258 ; $B$. breve 8815; B. dentium 2243; $B$. infantis 2205; B. lactis Bb 12; B. longum 2259; $B$. longum BB 536; Bifidobacterium sp. 35612; Bifidobacterium sp. 35687; Propionibacterium freudenreichii shermanii 9093.

Additional file 3: Putative linoleic acid isomerase protein. Panel A. E. coli JM109(DE3) pOXO4 (lanes 1-4) and PEMYE3 (lanes 5- 8) induced with 0.5 mM IPTG. Samples taken after 1, 3, 6 and $12 \mathrm{~h}$ growth for protein extraction and SDS-PAGE. Panel B. C. glutamicum PCLIK (lane 1) and pMYC2 (lane 2) following $24 \mathrm{~h}$ growth prior to protein extraction. Panel C. L. lactis pNZ4848 (lanes 1-2) and pEMYL1 (lanes 3-4) following induction with nisin 0 and $10 \mathrm{ng} / \mathrm{ml}$, respectively, and further growth for $12 \mathrm{~h}$ prior to protein extraction.

Additional file 4: CLA forming activity in bacterial strains expressing MCRA from B. breve. GC chromatogram of supernatant from $B$. breve NCIMB 702258 (positive control), L. lactis pEMYL1 (carrying laiA gene), and $L$. lactis pNZ8048 (vector control) following growth in linoleic acid $(0.1 \mathrm{mg} / \mathrm{ml})$ (L. lactis) and $(0.5 \mathrm{mg} / \mathrm{ml}$ (B. breve) for $48-72 \mathrm{~h}$. Similar results were obtained for recombinant C. glutamicum and E. coli.

Additional file 5: Hydratase activity in bacterial strains expressing MCRA from B. breve. Amounts of 10-HOA (black bars) and 10-HOE (gray bars) in supernatant from L. lactis PEMYL1 (carrying MCRA gene), and L. lactis pNZ8048 (VC, vector control) following growth in linoleic acid (0.1 $\mathrm{mg} / \mathrm{ml}$ ) (L. lactis) for 2-30 h. Data represent the mean values of 3 measurements. Similar results were obtained for recombinant $C$. glutamicum

\section{Abbreviations}

10,13-DiHOA: 10,13-dihydroxy octadecanoic acid; FAD: flavin adenine dinucleotide; FMN: flavin adenine mononucleotide; HEPES: 4-(2hydroxyethyl)- 1 -piperazine ethane-sulfonic acid; 10-HOA: 10-hydroxy octadecanoic acid; 10-HOE: (12Z)-10- hydroxy-12-octadecenoic acid; HPLC: high pressure liquid chromatography; MCRA: myosin cross-reactive antigen; MS: mass-spectroscopy; PAl: Propionibacterium acnes isomerase; Tris: 2Amino-2-(hydroxymethyl)propane- 1, 3-diol,

\section{Acknowledgements}

This study was funded by Science Foundation Ireland, through the Alimentary Pharmabiotic Centre, which is a research centre funded by SFI (grants 02/CE/B 124 and 07/CE/B1368), the Irish Government's National Development Plan and The European Union (Project QLK1-2002-02362). AL was founded by a Georg-Christoph-Lichtenberg stipend of the Ph. D. program "Molecular Biology".

\section{Author details}

${ }^{1}$ Alimentary Pharmabiotic Centre, Cork, Ireland. ${ }^{2}$ Microbiology Department, University College Cork, Cork, Ireland. ${ }^{3}$ Department Plant Biochemistry, Albrecht-von-Haller-Institute, Georg-August-University Göttingen, Göttingen, Germany. ${ }^{4}$ Teagasc Food Research Centre, Moorepark, Fermoy, Co. Cork, Ireland.

\section{Authors' contributions}

ER-C: collection and analysis of data, writing of manuscript, AL: collection and analysis of data, CG: collection and analysis of data RPR: design of experiments, editing of manuscript, OOS: collection and analysis of data, SFFF: design of experiments, GF: design of experiments IF: design of experiments, analysis of data and writing of manuscript, and CS: design of experiments, data analysis and editing of manuscript. All authors have read and approved the final manuscript.

Received: 19 May 2010 Accepted: 17 February 2011

Published: 17 February 2011

\section{References}

1. Volkov A, Liavonchanka A, Kamneva O, Fiedler T, Goebel C, Kreikemeyer B, Feussner I: Myosin cross-reactive antigen of Streptococcus pyogenes M49 encodes a fatty acid double bond hydratase that plays a role in oleic acid detoxification and bacterial virulence. J Biol Chem 1035, 285:3-61.

2. Bevers LE, Pinkse MW, Verhaert PD, Hagen WR: Oleate hydratase catalyzes the hydration of a nonactivated carbon-carbon bond. J Bacteriol 2009, 191:5010-2.

3. Bischoff M, Dunman P, Kormanec J, Macapagal D, Murphy E, Mounts W, Berger-Bachi B, Projan S: Microarray-based analysis of the Staphylococcus aureus sigmaB regulon. J Bacterio/ 2004, 186:4085-99.

4. Davies MR, McMillan DJ, Beiko RG, Barroso V, Geffers R, Sriprakash KS, Chhatwal GS: Virulence profiling of Streptococcus dysgalactiae subspecies equisimilis isolated from infected humans reveals 2 distinct genetic lineages that do not segregate with their phenotypes or propensity to cause diseases. Clin Infect Dis 2007, 44:1442-54.

5. Graham MR, Virtaneva K, Porcella SF, Gardner DJ, Long RD, Welty DM, Barry WT, Johnson CA, Parkins LD, Wright FA, et al: Analysis of the transcriptome of group A Streptococcus in mouse soft tissue infection. Am J Pathol 2006, 169:927-42.

6. Virtaneva K, Porcella SF, Graham MR, Ireland RM, Johnson CA, Ricklefs SM, Babar I, Parkins LD, Romero RA, Corn GJ, et al: Longitudinal analysis of the group A Streptococcus transcriptome in experimental pharyngitis in cynomolgus macaques. Proc Natl Acad Sci USA 2005, 102:9014-9.

7. Dunman PM, Murphy E, Haney S, Palacios D, Tucker-Kellogg G, Wu S, Brown EL, Zagursky RJ, Shlaes D, Projan SJ: Transcription profiling-based identification of Staphylococcus aureus genes regulated by the agr and/ or sarA loci. J Bacterio/ 2001, 183:7341-53.

8. Chaussee MA, Callegari EA, Chaussee MS: Rgg regulates growth phasedependent expression of proteins associated with secondary metabolism and stress in Streptococcus pyogenes. J Bacteriol 2004, 186:7091-9.

9. Luong TT, Dunman PM, Murphy E, Projan SJ, Lee CY: Transcription Profiling of the mgrA Regulon in Staphylococcus aureus. J Bacterio/ 2006, 188:1899-910.

10. Rosson R, Grund A, Deng M, Sanchez-Riera F: Linoleate isomerase. Book Linoleate isomerase City; 2004, (Editor ed.^eds.)

11. Kepler CR, Hirons KP, MCNeill JJ, Tove SB: Intermediates and products of the biohydrogenation of linoleic acid by Butyrinvibrio fibrisolvens. J Biol Chem 1966, 241:1350-4.

12. Harfoot CG, Hazelwood GP: Lipid metabolism in the rumen. In The Rumen Microbial Eco-system. Edited by: PN Hobson. London: Elsevier Applied Science Publishers; 1997:285-322.

13. Fujimoto K, Kimoto H, Shishikura M, Endo T, Ogimoto K: Biohydrogenation of linoleic acid by anaerobic bacteria isolated from the rumen. Bioscience Biotechnology and Biochemistry 1993, 57:1026-1027.

14. Ogawa J, Matsumura K, Kishino S, Omura Y, Shimizu S: Conjugated linoleic acid accumulation via 10-hydroxy-12-octadecaenoic acid during microaerobic transformation of linoleic acid by Lactobacillus acidophilus. Appl Environ Microbiol 2001, 67:1246-52.

15. Rosberg-Cody E, Ross RP, Hussey S, Ryan CA, Murphy BP, Fitzgerald GF, Devery $R$, Stanton C: Mining the microbiota of the neonatal gastrointestinal tract for conjugated linoleic acid-producing bifidobacteria. Appl Environ Microbiol 2004, 70:4635-41.

16. Coakley M, Fitzgerald G, Ros RP: Application and evaluation of the phage resistance- and bacteriocin-encoding plasmid pMRC01 for the improvement of dairy starter cultures. Appl Environ Microbiol 1997, 63:1434-40.

17. Barrett E, Ross RP, Fitzgerald GF, Stanton C: Rapid screening method for analyzing the conjugated linoleic acid production capabilities of bacterial cultures. Appl Environ Microbiol 2007, 73:2333-7.

18. Wall R, Ross RP, Shanahan F, O'Mahony L, O'Mahony C, Coakley M, Hart O, Lawlor P, Quigley EM, Kiely B, et al: Metabolic activity of the enteric 
microbiota influences the fatty acid composition of murine and porcine liver and adipose tissues. Am J Clin Nutr 2009, 89:1393-401.

19. Rosson R, Grund A, Deng M, Sanchez-Riera F: Linoleate isomerase. Book Linoleate isomerase City; 1999, (Editor ed.^eds.)

20. Altschul SF, Gish W, Miller W, Myers EW, Lipman DJ: Basic local alignment search tool. J Mol Biol 1990, 215:403-10.

21. Hoffman CS, Winston F: A ten-minute DNA preparation from yeast efficiently releases autonomous plasmids for transformation of Escherichia coli. Gene 1987, 57:267-72.

22. de Ruyter PG, Kuipers OP, de Vos WM: Controlled gene expression systems for Lactococcus lactis with the food-grade inducer nisin. App Environ Microbiol 1996, 62:3662-7.

23. Luchansky JB, Muriana PM, Klaenhammer TR: Application of electroporation for transfer of plasmid DNA to Lactobacillus, Lactococcus, Leuconostoc, Listeria, Pediococcus, Bacillus, Staphylococcus, Enterococcus and Propionibacterium. Mol Microbiol 1988 2:637-46.

24. de Ruyter PG, Kuipers OP, Meijer WC, de Vos WM: Food-grade controlled lysis of Lactococcus lactis for accelerated cheese ripening. Nat Biotechnol 1997, 15:976-9.

25. Laemmli UK: Cleavage of structural proteins during the assembly of the head of bacteriophage T4. Nature 1970, 227:680-5.

26. Bligh EG, Dyer WJ: A rapid method of total lipid extraction and purification. Can J Biochem Physiol 1959, 37:911-7.

27. Hornung E, Krueger C, Pernstich C, Gipmans M, Porzel A, Feussner I: Production of (10E,12Z)-conjugated linoleic acid in yeast and tobacco seeds. Biochim Biophys Acta 2005, 1738:105-14.

28. Notredame C, Higgins DG, Heringa J: T-Coffee: A novel method for fast and accurate multiple sequence alignment. I Mol Biol 2000, 302.205-17.

29. Felsenstein J: PHYLIP (PHYLogeny Inference Package) version 3.66. 2006

30. Huson DH, Richter DC, Rausch C, Dezulian T, Franz M, Rupp R.

Dendroscope: An interactive viewer for large phylogenetic trees. BMC Bioinformatics 2007, 8:460.

31. Feussner I, Hornung E, Liavonchanka A: Method for producing Hydroxy Fatty Acids. Book Method for producing Hydroxy Fatty Acids City; 2008, (Editor ed.^eds.), vol. WO/2008/1 19735

32. Wallen $L L$, Benedict RG, Jackson RW: The microbiological production of 10-hydroxystearic acid from oleic acid. Arch Biochem Biophys 1962 99:249-53.

33. O'Flaherty SJ, Klaenhammer TR: Functional and phenotypic characterization of a protein from Lactobacillus acidophilus involved in cell morphology, stress tolerance and adherence to intestinal cells. Microbiology 2010, 156:3360-7.

34. Liavonchanka A, Rudolph MG, Tittmann K, Hamberg M, Feussner I: On the mechanism of a polyunsaturated fatty acid double bond isomerase from Propionibacterium acnes. J Biol Chem 2009, 284:8005-12.

35. Desmond C, Fitzgerald GF, Stanton C, Ross RP: Improved stress tolerance of GroESL-overproducing Lactococcus lactis and probiotic Lactobacillus paracasei NFBC 338. Appl Environ Microbiol 2004, 70:5929-36.

36. Piper PW: The heat shock and ethanol stress responses of yeast exhibit extensive similarity and functional overlap. FEMS Microbiol Lett 1995, 134:121-127.

doi:10.1186/1471-2091-12-9

Cite this article as: Rosberg-Cody et al: Myosin-cross-reactive antigen (MCRA) protein from Bifidobacterium breve is a FAD-dependent fatty acid hydratase which has a function in stress protection. $B M C$

Biochemistry 2011 12:9.

\section{Submit your next manuscript to BioMed Central and take full advantage of:}

- Convenient online submission

- Thorough peer review

- No space constraints or color figure charges

- Immediate publication on acceptance

- Inclusion in PubMed, CAS, Scopus and Google Scholar

- Research which is freely available for redistribution

Submit your manuscript at www.biomedcentral com/submit
Biomed Central 